\title{
A combined analysis of outcome following breast cancer: differences in survival based on BRCA1/BRCA2 mutation status and administration of adjuvant treatment
}

\author{
Mark E Robson ${ }^{1 \dagger}$, Pierre O Chappuis ${ }^{2 \star+}$, Jaya Satagopan ${ }^{3}$, Nora Wong $^{4}$, Jeff Boyd ${ }^{5}$, \\ John R Goffin ${ }^{6 *}$, Clifford Hudis ${ }^{1}$, David Roberge ${ }^{6}$, Larry Norton ${ }^{1}$, Louis R Bégin ${ }^{7 *}$, Kenneth Offit ${ }^{1}$ \\ and William D Foulkes $2,4,8$
}

\author{
${ }^{1}$ Department of Medicine, Memorial Sloan-Kettering Cancer Center, New York, New York, USA \\ ${ }^{2}$ Research Institute of McGill University Health Centre, Cancer Prevention Centre, McGill University, Montreal, Quebec, Canada \\ ${ }^{3}$ Department of Epidemiology/Biostatistics, Memorial Sloan-Kettering Cancer Center, New York, New York, USA \\ ${ }^{4}$ Cancer Prevention Centre, Sir Mortimer B Davis-Jewish General Hospital, McGill University, Montreal, Quebec, Canada \\ ${ }^{5}$ Department of Surgery, Memorial Sloan-Kettering Cancer Center, New York, NY, USA \\ ${ }^{6}$ Department of Oncology, McGill University, Montreal, Quebec, Canada \\ ${ }^{7}$ Department of Pathology, McGill University, Montreal, Quebec, Canada \\ ${ }^{8}$ Program in Cancer Genetics, Departments of Oncology and Human Genetics, McGill University, Montreal, Quebec, Canada \\ *Current addresses: Divisions of Oncology and Medical Genetics, University Hospitals of Geneva, Geneva, Switzerland (POC); Hôpital du Sacré- \\ Coeur de Montréal, Montreal, Quebec, Canada (LRB); and Division of Hematology/Oncology, Department of Medicine, Tufts University, Tufts \\ University-New England Medical Center, Boston, Massachusetts, USA (JRG) \\ ${ }^{\dagger} \mathrm{MER}$ and POC contributed equally to this manuscript
}

Corresponding author: William D Foulkes (e-mail: william.foulkes@mcgill.ca)

Received: 8 Jul 2003 Revisions requested: 19 Aug 2003 Revisions received: 6 Sep 2003 Accepted: 15 Sep 2003 Published: 24 Oct 2003

Breast Cancer Res 2004, 6:R8-R17 (DOI 10.1186/bcr658)

(C) 2004 Robson et al., licensee BioMed Central Ltd (Print ISSN 1465-5411; Online ISSN 1465-542X). This is an Open Access article: verbatim copying and redistribution of this article are permitted in all media for any purpose, provided this notice is preserved along with the article's original URL.

See related Commentary: http://breast-cancer-research.com/content/6/1/E7

\begin{abstract}
Background: The prognostic significance of germline mutations in BRCA1 and BRCA2 in women with breast cancer remains unclear. A combined analysis was performed to address this uncertainty.
\end{abstract}

Methods: Two retrospective cohorts of Ashkenazi Jewish women undergoing breast-conserving treatment for invasive cancer between 1980 and $1995(n=584)$ were established. Archived tissue blocks were used as the source of DNA for Ashkenazi Jewish BRCA1/BRCA2 founder mutation analysis. Paraffin-embedded tissue and follow-up information was available for 505 women.

Results: Genotyping was successful in 496 women, of whom $56(11.3 \%)$ were found to carry a BRCA1/BRCA2 founder mutation. After a median follow-up period of 116 months, breast cancer specific survival was worse in women with BRCA1 mutations than in those without $(62 \%$ at 10 years versus $86 \% ; P<0.0001)$, but not in women with the BRCA2 mutation ( $84 \%$ versus $86 \%$ at 10 years; $P=0.76$ ). Germline $B R C A 1$ mutations were an independent predictor of breast cancer mortality in multivariate analysis (hazard ratio 2.4, 95\% confidence interval 1.2-4.8; $P=0.01)$. BRCA1 status predicted breast cancer mortality only among women who did not receive chemotherapy (hazard ratio 4.8, 95\% confidence interval 2.0-11.7; $P=0.001)$. The risk for metachronous ipsilateral cancer was not greater in women with germline $B R C A 1 / B R C A 2$ founder mutations than in those without mutations $(P=0.68)$.

Conclusion: BRCA1 mutations, but not BRCA2 mutations, are associated with reduced survival in Ashkenazi women undergoing breast-conserving treatment for invasive breast cancer, but the poor prognosis associated with germline $B R C A 1$ mutations is mitigated by adjuvant chemotherapy. The risk for metachronous ipsilateral disease does not appear to be increased for either $B R C A 1$ or BRCA2 mutation carriers, at least up to 10 years of follow up.

Keywords: adjuvant therapy, $B R C A 1, B R C A 2$, breast cancer, contralateral, ipsilateral, prognosis

$\mathrm{BCT}=$ breast-conserving therapy; $\mathrm{Cl}=$ confidence intervals; $\mathrm{HR}=$ hazard ratio; $\mathrm{MSKCC}=$ Memorial Sloan-Kettering Cancer Center; PCR $=$ polymerase chain reaction; SMBD-JGH = Sir Mortimer B. Davis-Jewish General Hospital. 


\section{Introduction}

The major breast cancer predisposing genes $B R C A 1$ and $B R C A 2$ were identified in 1994 and 1995, respectively $[1,2]$. Unfortunately, the optimal clinical approach to women who develop hereditary breast cancer remains incompletely defined. Studies of the outcomes of women with BRCA1/BRCA2-related cancer have yielded conflicting results. Several reports suggested that women with germline mutations in BRCA1 are more likely to die from their disease than are women with sporadic breast cancer [3-6]. However, other studies did not confirm these observations [7,8]. Fewer studies have focused on BRCA2-related breast cancer $[9,10]$.

Certain unique barriers have impeded the analysis of germline BRCA1/BRCA2 status as a prognostic factor. Because informed consent is required for genetic testing, and individuals may decline such testing for a variety of reasons, it has been difficult to develop prospective cohorts for outcome studies. On the other hand, testing generally requires the provision of a blood sample, which may introduce a survival bias in the conduct of retrospective studies. Both of these potential selection biases may be avoided through the use of a retrospective design in which BRCA1/BRCA2 mutations are sought in archival tissue from women who have undergone treatment for cancer, and in whom the clinical outcomes are known. Genetic testing is performed on anonymized tissue specimens, and comparisons are made between the women who do and those who do not have mutations. This design presupposes that the BRCA1/BRCA2 mutation spectrum in the study group is limited and predefined. This is the case for women of Ashkenazi Jewish descent, because two specific mutations of BRCA1 (185delAG and $5382 \mathrm{ins} C$ ) and one mutation of BRCA2 (6174delT) constitute the great majority of mutations identified in this population, and these are easily detectable in paraffin-embedded material [11-14]. The present study employed this retrospective, anonymized design to examine the outcomes of Ashkenazi women with invasive breast cancer undergoing breast-conserving therapy (BCT) at two institutions in the USA and Canada.

\section{Methods}

\section{Patients}

Patients from Memorial Sloan-Kettering Cancer Center (MSKCC) were identified as previously described [15]. Briefly, clinical databases from the Departments of Pathology, Surgery, and Radiation Therapy were reviewed to identify women who underwent BCT (wide local excision and radiation, with or without axillary node dissection) between 1 January 1980 and 31 December 1990. Hospital registration databases were then cross-referenced to identify women expressing Jewish religious preference. Of the 393 Jewish women undergoing BCT, paraffin-embedded tissue and follow-up information was available for
314 women. Information on tumor grade was not available. The combined impact of germline mutations in $B R C A 1 / B R C A 2$ on prognosis in this group of women was reported in a previous publication [15]. For the present study the clinical database was extended and additional analyses were performed evaluating the prognostic impact of interactions between germline status, hormone receptor status, and adjuvant treatment with either tamoxifen or chemotherapy. The clinical impact of germline mutations in BRCA1 and BRCA2 were considered separately.

Ashkenazi Jewish women diagnosed with invasive nonmetastatic breast cancer at age 65 years or less, who were treated at Sir Mortimer B. Davis-Jewish General Hospital (SMBD-JGH) between 1 January 1980 and 1 November 1995, were identified from the Medical Records Department. Of 292 women identified, 225 underwent breast-conserving surgery. Of these 225 women, 34 did not receive radiation and are excluded from further consideration. Paraffin-embedded tissue and follow-up information was available for the remaining 191 women, who were included in the analysis. Results relating to germline mutations in BRCA1 for the entire dataset were recently reported [16]. The study was focused on those receiving BCT to harmonize the ascertainment criteria between the two centers and to focus on ipsilateral cancer recurrence. The two studies were combined to increase the sample size and thereby the power to observe the separate effects of mutations in BRCA1 and BRCA2, which was not previously possible with either dataset alone.

\section{Data collection}

Study procedures at each institution were approved by the local institutional review board. For each subject, paraffin-embedded material was retrieved from hospital tissue banks and clinical records were reviewed. In order to comply with guidelines regarding the conduct of genetic research on stored tissue samples, only a limited amount of clinical data was extracted from the medical record, including age at diagnosis ( $<50$ or $\geq 50$ years), tumor size $(\leq 2 \mathrm{~cm}$ or $>2 \mathrm{~cm}$ ), lymph node involvement (present or absent), hormone receptor status (if available), and adjuvant treatment with chemotherapy or tamoxifen. Time to development of local or distant recurrence was recorded, as was the time to development of contralateral breast cancer, if any. Clinical follow-up information was obtained by chart review, tumor registry query, and contact with the treating physician. The tissue specimen and clinical data for each subject were associated through a unique study identifier. At MSKCC, the link between study identifier and patient identifying information was irretrievably destroyed before genetic analysis was performed. At the SMBD-JGH, the mutation results were anonymized and separated from any personal identifiers in a manner approved by the local institutional review board. 


\section{Genetic analysis}

Analysis of the paraffin-embedded specimens was performed as previously described $[3,15]$. Briefly, paraffin sections were obtained from the retrieved tissue blocks and genomic DNA was isolated by standard protocols. At MSKCC normal lymph node was preferentially examined, whereas at SMBD-JGH tumor tissue was studied. All specimens were analyzed by PCR amplification of the regions surrounding the Ashkenazi founder mutations 185delAG and 5382insC in BRCA1 and 6174delT in $B R C A 2$. Radiolabeled PCR products were visualized by denaturing PAGE followed by autoradiography. The detection of characteristic variant bands indicated the presence of the mutation being studied. Variant bands were confirmed by direct sequencing or by an independent PCR amplification of the corresponding DNA sample and repeat analysis. There were no discordant results upon repeat analysis.

DNA samples from nine patients failed to yield PCR products despite repeat analysis. Therefore, the final study group consisted of 496 women. There were 24 women who underwent contralateral BCT for metachronous breast cancer during the period of the study. Thus, for the purposes of determining the rate of metachronous ipsilateral cancer, there were 520 breasts at risk in the dataset.

\section{Statistical analyses}

Clinical characteristics of women with and without germline BRCA1/BRCA2 founder mutations were compared using a $\chi^{2}$ test. For the survival analyses, breast cancer specific mortality was chosen as the main endpoint for the study in order to avoid possible confounding by death due to other causes, such as malignancies of other anatomic sites. Overall survival, defined as the time from diagnosis to death from any cause, was evaluated as a secondary end-point. All ipsilateral breast cancer events were considered in the calculation of the cumulative incidence of metachronous ipsilateral breast cancer, because the retrospective design of this study did not allow reliable discrimination between true recurrences and separate metachronous primaries. All contralateral breast cancer diagnoses were considered new primary lesions for the purposes of calculating the cumulative incidence of contralateral breast cancer. Women who had undergone contralateral mastectomy before the breast cancer diagnosis for which they underwent breast conservation $(n=7)$ were excluded from the analysis of this end-point.

Patients were censored if they had not experienced the end-point of interest at the time of last follow up. Kaplan-Meier estimates of breast cancer specific survival time were compared using the log-rank test. A Cox proportional hazards model was used to estimate the hazard ratios (HRs) for breast cancer specific survival time under after accounting for death due to causes other than breast cancer as a competing risk. The cumulative incidences of the end-points in women with and without mutations were compared with a $\chi^{2}$ test fit using the method of Gray [17]. $P$ values comparing the overall curves corresponding to the end-point of interest are provided for these univariate comparisons. The cumulative incidences of death due to breast cancer and due to causes other than breast cancer are both calculated in the same analysis, and shown in separate figures. Multivariate proportional hazards models accounting for non-breast-cancer death as a competing risk were fitted using the method of Fine and Gray [18]. All $P$ values were calculated using two-sided tests.

\section{Results}

Mutation analysis and clinical characteristics

$B R C A 1 / B R C A 2$ mutations were identified in 56 (11.3\%) of 496 patients (42BRCA1 [32 women carried the 185delAG and 10 carried the 5382ins $C$ mutation], $13 B R C A 2$ [all 6174delT], and one both BRCA1 and $B R C A 2$ [185delAG and 6174delT]). The clinical characteristics of women with $B R C A 1, B R C A 2$, and no germline BRCA1/BRCA2 mutations are presented in Table 1. Women with germline BRCA1 mutations were significantly more likely than women without these specific mutations to be diagnosed before the age of 50 years, to be diagnosed with estrogen receptor negative tumors, and to have received adjuvant chemotherapy. BRCA1 mutation carriers were significantly less likely than noncarriers to have received tamoxifen (Table 1). In women with BRCA1 mutations, neither tumor size nor axillary nodal involvement differed significantly from noncarriers. Among those for whom data were available, BRCA2 mutation carriers were more likely than $B R C A 1$ carriers to have estrogen receptor positive tumours (odds ratio 10.5; $P=0.004$ ) and to have received adjuvant tamoxifen (odds ratio $5.4 ; P=0.02$ ). For no other variable was the distribution significantly different between BRCA2 mutation carriers and either $B R C A 1$ carriers or noncarriers.

\section{Breast cancer specific survival}

The median follow-up period for surviving women was 116 months. There were 79 women who died from breast cancer, 34 who died from causes other than breast cancer, and one whose cause of death was unknown. There were 18 deaths due to breast cancer among the 57 women with $B R C A 1 / B R C A 2$ mutations. Sixteen deaths occurred among $43 B R C A 1$ carriers and two among $14 B R C A 2$ carriers, and there were 61 breast cancer related deaths among the 439 women who did not have a detectable $B R C A 1 / B R C A 2$ mutation. At 10 years, the cumulative incidence of death due to breast cancer among $B R C A 1 / B R C A 2$ mutation carriers was $33 \%$, as compared with $14 \%$ among noncarriers $(P=0.0002)$. However, the negative impact of mutation status was not evenly distributed among BRCA1/BRCA2 carriers, 
Table 1

Clinical characteristics of women with and without BRCA founder mutations

\begin{tabular}{|c|c|c|c|c|c|}
\hline Variable & $\begin{array}{l}\text { No } B R C A \text { founder } \\
\text { mutation }(n=440)\end{array}$ & $\begin{array}{c}\text { BRCA1 founder } \\
\text { mutation }(n=43)^{+}\end{array}$ & $\begin{array}{l}P(B R C A 1 \text { versus no } \\
\text { founder mutation)* }\end{array}$ & $\begin{array}{l}\text { BRCA2 founder } \\
\text { mutation }(n=14)^{+}\end{array}$ & $\begin{array}{c}P(B R C A 2 \text { versus } \\
\text { no founder mutation)* }\end{array}$ \\
\hline \multicolumn{6}{|c|}{ Age at diagnosis (years) } \\
\hline$<50$ & $135(31 \%)$ & $30(70 \%)$ & $<0.0001$ & $4(29 \%)$ & NS \\
\hline$\geq 50$ & 305 (69\%) & $13(30 \%)$ & & $10(71 \%)$ & \\
\hline \multicolumn{6}{|l|}{ Tumor size } \\
\hline $\mathrm{T} 1$ & $324(74 \%)$ & $29(67 \%)$ & NS & $8(57 \%)$ & NS \\
\hline T2 & $97(22 \%)$ & $11(26 \%)$ & & $4(29 \%)$ & \\
\hline Unknown & $19(4 \%)$ & $3(7 \%)$ & & $2(14 \%)$ & \\
\hline \multicolumn{6}{|c|}{ Nodal involvement } \\
\hline Present & $149(34 \%)$ & $18(42 \%)$ & NS & $6(43 \%)$ & NS \\
\hline Absent & $262(60 \%)$ & $23(53 \%)$ & & $6(43 \%)$ & \\
\hline Unknown & $29(6 \%)$ & $2(5 \%)$ & & $2(14 \%)$ & \\
\hline \multicolumn{6}{|c|}{ Estrogen receptor } \\
\hline Positive & $197(45 \%)$ & $6(14 \%)$ & $<0.0001$ & $7(50 \%)$ & NS \\
\hline Negative & $98(22 \%)$ & $27(63 \%)$ & & $3(21 \%)$ & \\
\hline Unknown & $145(33 \%)$ & $10(23 \%)$ & & $4(29 \%)$ & \\
\hline \multicolumn{6}{|l|}{ Chemotherapy } \\
\hline Yes & $156(35 \%)$ & $24(56 \%)$ & 0.02 & $7(50 \%)$ & NS \\
\hline No & $257(58 \%)$ & $17(40 \%)$ & & $7(50 \%)$ & \\
\hline Unknown & $27(10 \%)$ & $2(4 \%)$ & & $0(0 \%)$ & \\
\hline \multicolumn{6}{|l|}{ Tamoxifen } \\
\hline Yes & $190(43 \%)$ & $10(23 \%)$ & 0.01 & $9(64 \%)$ & NS \\
\hline No & $203(46 \%)$ & $30(70 \%)$ & & $5(36 \%)$ & \\
\hline Unknown & $47(11 \%)$ & $3(7 \%)$ & & $0(0 \%)$ & \\
\hline
\end{tabular}

${ }^{*}$ Cases in which the characteristic of interest is unknown are not included in the comparisons. ${ }^{+}$Woman with both $B R C A 1$ and $B R C A 2$ founder mutations are included in both groups, hence the total number women listed here is 497.

because the probability of death due to breast cancer among BRCA1 mutation carriers was $38 \%$ at 10 years $(P<0.0001$, versus noncarriers; Fig. 1 and Table 2$)$ and $15.5 \%$ among women with the BRCA2 founder mutation $(P=0.76$ versus non-carriers; Table 2$)$. There was no difference between women with and those without $B R C A 1 / B R C A 2$ mutations with respect to the probability of death due to causes other than breast cancer $(P=0.38$; Fig. 2).

In univariate analyses, age under 50 years at initial diagnosis, presence of a BRCA1 mutation, primary tumor size greater than $2 \mathrm{~cm}$, estrogen receptor negativity, axillary nodal involvement, and receipt of adjuvant chemotherapy were all significantly associated with poorer breast cancer specific survival (Table 2). Adjuvant treatment was not randomly assigned, and therefore the association between administration of chemotherapy and a poor outcome $(P<0.0001)$ is probably accounted for by the fact that women who were given chemotherapy had a higher a priori probability of death than did those not receiving adjuvant chemotherapy. For this reason, use of chemotherapy was not included as a variable in the final multivariate model. In a multivariate competing risk analysis of breast cancer specific survival, we included only those variables that were significant in the univariate analysis. The final, most parsimonious model is shown in Table 3. BRCA1 mutation status retained independent prognostic significance (HR 2.39, 95\% confidence interval [Cl] 1.20-4.75; $P=0.01$ ), along with tumor size greater than $2 \mathrm{~cm}$ (HR 2.19, 95\% Cl 1.30-3.67; $P=0.003$ ) and axillary nodal involvement (HR 1.78, 95\% Cl 1.07-2.96; $P=0.03)$. Women diagnosed after the age of 50 years were less likely to die from breast cancer than were 
Figure 1

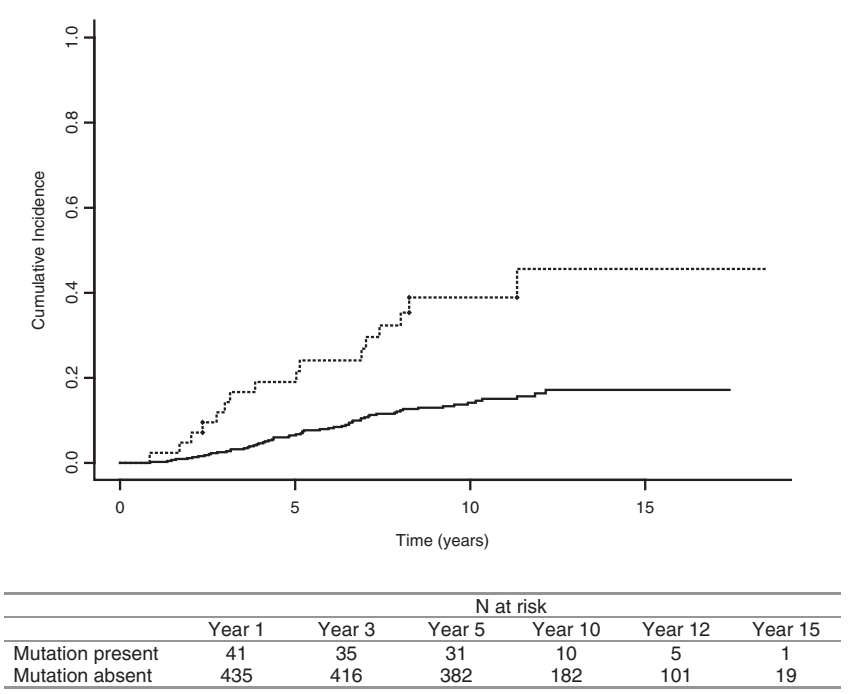

Cumulative incidence of death due to breast cancer among women with (…) and those without (-) germline BRCA1 mutations $(P<0.0001)$.

\section{Figure 2}

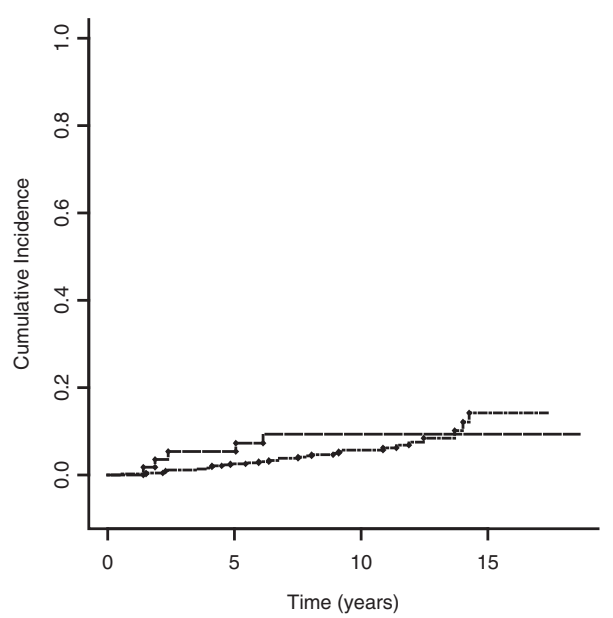

\begin{tabular}{lcccccc}
\hline & \multicolumn{6}{c}{ N at risk } \\
\hline & Year 1 & Year 3 & Year 5 & Year 10 & Year 12 & Year 15 \\
\hline Mutation present & 55 & 46 & 40 & 12 & 7 & 2 \\
Mutation absent & 435 & 416 & 382 & 182 & 101 & 19 \\
\hline
\end{tabular}

Cumulative incidence of death due to causes other than breast cancer in women with $(--)$ and in those without $(-\cdot-)$ germline BRCA mutations $(P=0.38)$

younger women (HR 0.55, 95\% $\mathrm{Cl} 0.33-0.92 ; P=0.02$; Table 3$)$. The models were essentially unchanged when overall survival was the end-point. The presence of the BRCA2 mutation was not a significant prognostic factor in either univariate (Table 2) or multivariate analysis (data not
Table 2

\begin{tabular}{|c|c|c|c|}
\hline Variable & $n$ & Breast cancer deaths $(n)$ & $P$ \\
\hline \multicolumn{4}{|l|}{$B R C A$ mutation } \\
\hline Any & 56 & 18 & 0.0002 \\
\hline None & 439 & 61 & \\
\hline \multicolumn{4}{|l|}{$B R C A 1$ mutation } \\
\hline Mutation present & 43 & 16 & $<0.0001$ \\
\hline Mutation absent & 439 & 61 & \\
\hline \multicolumn{4}{|l|}{$B R C A 2$ mutation } \\
\hline Mutation present & 14 & 2 & 0.76 \\
\hline Mutation absent & 439 & 61 & \\
\hline \multicolumn{4}{|l|}{ Tumor size } \\
\hline$\leq 2 \mathrm{~cm}$ & 360 & 41 & $<0.0001$ \\
\hline$>2 \mathrm{~cm}$ & 111 & 31 & \\
\hline \multicolumn{4}{|l|}{ Axillary node } \\
\hline Negative & 290 & 31 & $<0.0001$ \\
\hline Positive & 172 & 44 & \\
\hline \multicolumn{4}{|l|}{ Estrogen receptor } \\
\hline Positive & 210 & 28 & 0.01 \\
\hline Negative & 127 & 31 & \\
\hline \multicolumn{4}{|c|}{ Age at diagnosis (years) } \\
\hline$<50$ & 169 & 42 & $<0.0001$ \\
\hline$\geq 50$ & 326 & 37 & \\
\hline \multicolumn{4}{|l|}{ Chemotherapy } \\
\hline Yes & 187 & 48 & $<0.0001$ \\
\hline No & 279 & 30 & \\
\hline \multicolumn{4}{|l|}{ Tamoxifen } \\
\hline Yes & 208 & 28 & 0.14 \\
\hline No & 237 & 47 & \\
\hline
\end{tabular}

\section{Effect of adjuvant treatment}

Of the 468 women in the study for whom information regarding adjuvant chemotherapy was available, 187 received chemotherapy and 281 did not. In univariate analysis the presence of a germline BRCA1 mutation was significantly associated with a worse breast cancer specific survival both among those women who received chemotherapy (10-year breast cancer mortality $41 \%$ in carriers versus $24 \%$ in noncarriers; $P=0.04$ ) and among those who did not (10-year breast cancer mortality $24 \%$ in carriers versus $9.6 \%$ in noncarriers; $P=0.008$ ). The presence of a germline BRCA1 mutation remained an independent predictor of breast cancer mortality in multivariate 
Table 3

\begin{tabular}{|c|c|c|c|c|}
\hline Variable & $n$ & $\begin{array}{c}\text { Deaths due } \\
\text { to breast } \\
\text { cancer }(n)\end{array}$ & $\begin{array}{l}\text { Hazard ratio } \\
(95 \% \mathrm{Cl})\end{array}$ & $P$ \\
\hline \multicolumn{5}{|c|}{$B R C A 1$ mutation } \\
\hline No mutation & 397 & 52 & 1.00 & 0.01 \\
\hline$B R C A 1$ & 37 & 14 & $2.39(1.20-4.75)$ & \\
\hline \multicolumn{5}{|l|}{ Tumor size } \\
\hline$<2 \mathrm{~cm}$ & 333 & 39 & 1.00 & 0.003 \\
\hline$\geq 2 \mathrm{~cm}$ & 101 & 27 & $2.19(1.30-3.67)$ & \\
\hline \multicolumn{5}{|l|}{ Axillary node } \\
\hline Negative & 280 & 31 & 1.00 & 0.03 \\
\hline Positive & 154 & 35 & $1.78(1.07-2.96)$ & \\
\hline \multicolumn{5}{|l|}{ Age (years) } \\
\hline$<50$ & 146 & 34 & 1.00 & 0.02 \\
\hline$\geq 50$ & 288 & 32 & $0.55(0.33-0.92)$ & \\
\hline
\end{tabular}

$\mathrm{Cl}$, confidence interval

analysis of the group of women who did not receive chemotherapy (HR 4.8,95\% Cl 2.0-11.7; $P=0.001$ ), but not in those women who did receive adjuvant chemotherapy (HR 1.5, 95\% Cl 0.66-3.49; $P=0.33$ ). There were 208 women who received adjuvant tamoxifen and 237 who did not. Tamoxifen usage was not a significant predictor of outcome in univariate analysis. However, in multivariate analysis, among those not receiving tamoxifen, the presence of a germline BRCA1 mutation was significantly associated with breast cancer specific survival (HR 3.5, 95\% Cl 1.7-7.2; $P=0.001$ ). By contrast, BRCA1 mutations had no prognostic value in those who did receive tamoxifen (HR 0.5, 95\% Cl 0.05-5.0; $P=0.55$ ).

\section{Ipsilateral and contralateral breast cancer}

A total of 496 patients in the present study underwent BCT for 520 invasive breast cancers. There was no significant difference between women with and those without $B R C A 1 / B R C A 2$ mutations in the risk for metachronous ipsilateral breast cancer at 10 years $(12 \%$ in women with mutations versus $8 \%$ in women without; $P=0.68$; Fig. 3 ). Age under 50 years at initial diagnosis was the only significant predictor of metachronous ipsilateral disease $(P=0.002)$. Women with mutations were significantly more likely to develop contralateral breast cancer at 10 years $(27 \%$ in women with mutations versus $8 \%$ in women without; $P<0.0001$, based on a competing cause analysis; Fig.4). The risk for contralateral cancer was similar in women with $B R C A 1$ mutations $(27 \%$ at 10 years) and in those with the BRCA2 mutation (32\% at 10 years). In univariate analyses, which were adjusted for
Figure 3

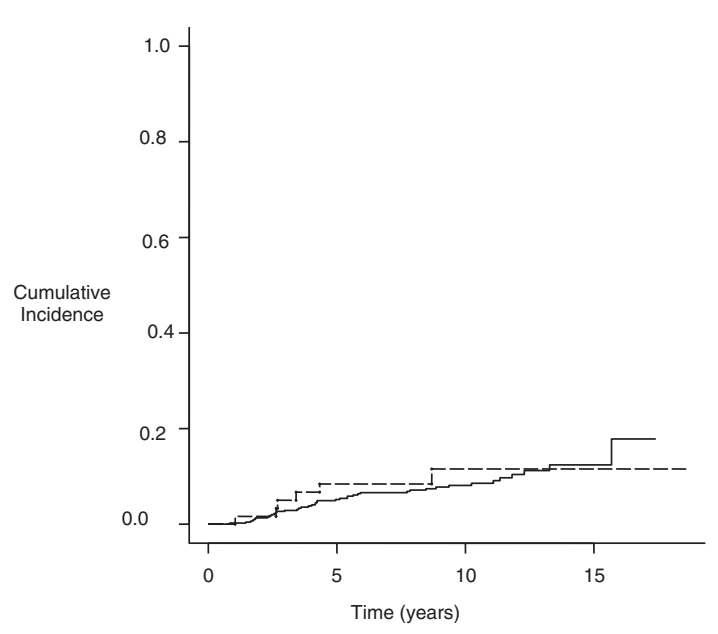

\begin{tabular}{lcccccc}
\hline & \multicolumn{7}{c}{ Breasts at risk } \\
\hline & Year 1 & Year 3 & Year 5 & Year 10 & Year 12 & Year 15 \\
\hline Mutation present & 61 & 48 & 39 & 10 & 5 & 5 \\
Mutation absent & 453 & 417 & 375 & 172 & 94 & 94 \\
\hline
\end{tabular}

Cumulative incidence of metachronous ipsilateral breast cancer in women with (- -$)$ and in those without $(-)$ germline BRCA mutations $(P=0.68)$.

death from competing causes, women not using tamoxifen experienced a higher incidence of ipsilateral breast cancer (HR 1.97, 95\% Cl 1.01-3.86; $P=0.05$ ). Those not using tamoxifen also had a marginally, nonsignificantly higher incidence of contralateral breast cancer (HR 1.26, 95\% Cl $0.71-2.25 ; P=0.48$ ). Chemotherapy did not have a significant effect on either ipsilateral $(P=0.16)$ or contralateral $(P=0.36)$ breast cancer incidence. In an analysis restricted to mutation carriers, the contralateral breast cancer risk was lower in BRCA1/BRCA2 mutation carriers receiving tamoxifen than in those not receiving tamoxifen, although this did not reach statistical significance (risk ratio $0.47,95 \% \mathrm{Cl} 0.14-1.59 ; P=0.23$ ). The effect of tamoxifen on contralateral breast cancer risk was not significantly greater in women with a BRCA2 mutation than in women with BRCA1 mutations, although this analysis was limited by the small numbers of women in each group.

\section{Discussion}

Although $B R C A 1$ and $B R C A 2$ were identified in 1994 and 1995, the influence of germline BRCA1/BRCA2 mutations on the outcome of women with breast cancer has remained undefined. Several retrospective studies of affected mutation carriers identified by familial cancer risk clinics failed to demonstrate any differences in survival when women with mutations were compared with various control groups (for reviews $[19,20]$ ). However, because only women who survived their breast cancer were able to undergo genetic testing and be identified as mutation car- 


\section{Figure 4}

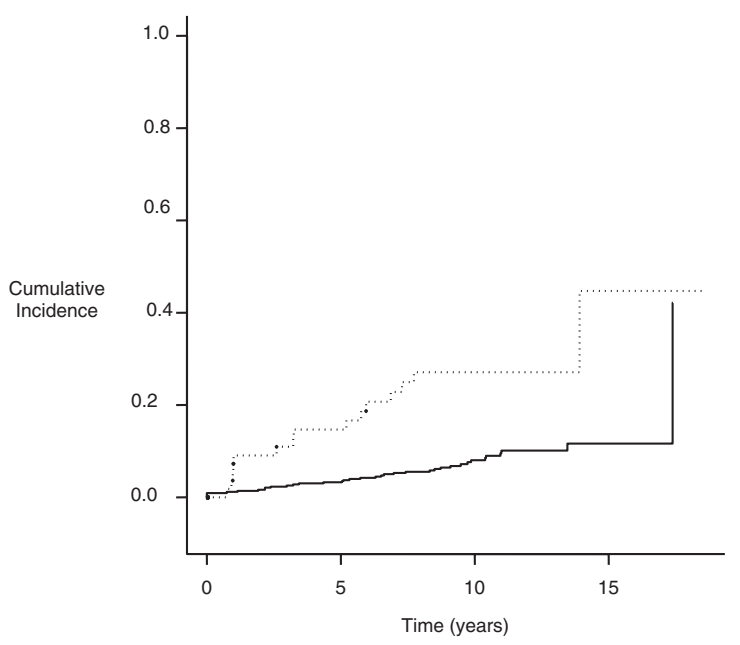

\begin{tabular}{lcccccc}
\hline & \multicolumn{7}{c}{$\mathrm{N}$ at risk } \\
\hline Mutation present & Year 1 & Year 3 & Year 5 & Year 10 & Year 12 & Year 15 \\
Mutation absent & 424 & 40 & 33 & 9 & 5 & 5 \\
\hline
\end{tabular}

Cumulative incidence of metachronous contralateral breast cancer in women with (‥) and in those without (-) germline BRCA mutations $(P<0.0001)$

riers in these prevalent series, a survival bias may have prevented the detection of a negative impact of BRCA1/BRCA2 mutations on outcome. The anonymized design of the current retrospective study circumvented this potential bias by ensuring that all patients within the study group were genotyped, without regard for vital status.

In the present study, women undergoing BCT for early stage invasive breast cancer demonstrated significantly shorter breast cancer specific and overall survival if they carried a germline BRCA1 mutation but not a BRCA2 mutation. This suggests that the clinical outcome of women with germline mutations may vary depending on which gene is mutated, and even possibly on the position of the mutation within a particular gene. However, the present study, examining the consequences of an intentionally restricted set of mutations in a limited sample, cannot definitively resolve this question. Larger studies, preferably of prospectively ascertained incident cohorts, are necessary.

The adverse prognosis conferred by a BRCA1 mutation was not attributable to differences in tumor size or axillary nodal status, which indicates that the impact of germline status on clinical outcome is not the result of an association with advanced stage at diagnosis. Several studies have demonstrated that breast cancers arising in women
$B R C A 1$, frequently manifest adverse pathologic and biologic features, such as high histologic grade, hormone receptor negativity, p53 mutation, aneuploidy, and high S-phase fraction [19]. Studies conducted in sporadic breast cancer have previously demonstrated the negative prognostic significance of each of these factors. Whether the prognostic significance of $B R C A 1 / B R C A 2$ status is completely independent of all of these other parameters cannot be resolved by the present study. BRCA1-related breast cancers in this series, as in others, were significantly more likely to be estrogen receptor negative than were cancers not associated with BRCA1 mutations, and estrogen receptor status was associated with breast cancer mortality in univariate analysis. However, germline status remained a significant prognostic indicator in the multivariate model, indicating that the adverse effect of mutation status on outcome is independent of the association with estrogen receptor negative phenotype. The robustness of this observation is limited to some degree by the fact that receptor status was unknown for a significant proportion of patients, in part because some of these cases were diagnosed before routine receptor testing and in part because the small size of some tumors prevented receptor determination using the dextran-coated charcoal method in use at the time.

The design of the present study precluded a separate analysis of the role of grade in determining outcome in $B R C A 1$ carriers. However, it is known that the majority of $B R C A 1$-related breast cancers are high grade, infiltrating ductal breast cancers [21]. It would not significantly change the conclusions of this study if it could be demonstrated that the independent negative impact observed is attributable to the 'downstream' phenotypic consequences of the presence of a BRCA1 mutation.

Some preclinical studies have demonstrated that mouse embryonic cells lacking functional Brca1 protein are sensitive to specific chemotherapeutic agents such as cisplatinum and mitomycin $C[22,23]$, and similar results have been seen in human breast cancer cells null for BRCA1 protein [24]. These observations have raised the possibility that human BRCA1-associated breast cancers might also be differentially sensitive to chemotherapy. The current analysis is consistent with this hypothesis, because the negative prognostic influence of a germline BRCA1 mutation appeared to be reduced in women receiving adjuvant chemotherapy, and, in fact, lost independent statistical significance in this group. Furthermore, standard chemotherapy regimens do not include mitomycin- $\mathrm{C}$ or cisplatinum, and it remains possible that $B R C A 1$-associated breast cancers may be even more sensitive to these agents. However, the design of the present study is such that these observations must be considered hypothesis generating. Further exploration should take place within the context of prospective trials. 
In the present study, women with germline mutations experienced a risk for metachronous ipsilateral breast cancer that was not significantly different from that in women without mutations. Several studies have described the incidence of subsequent ipsilateral disease in women with BRCA1/BRCA2 mutations undergoing BCT $[7,8,15,25,26]$. In these series, ipsilateral tumor recurrence rates ranged from $1 \%$ to $20 \%$ at 5 years, which are in the range previously reported in series of young women undergoing BCT. A recent analysis of mutation carriers who had survived a mean of 14 years after their breast cancer diagnosis [27] indicated a 49\% estimated risk for ipsilateral cancer after 10 years of follow up. However, studies such as this, which analyze prevalent groups of long-term survivors, may overestimate the risk that a newly diagnosed woman with a BRCA1/BRCA2 mutation will suffer an ipsilateral breast cancer, because a significant fraction of newly diagnosed women will unfortunately die from their breast cancer and thus will not have lived long enough to develop a second ipsilateral tumor. Thus, ipsilateral cancer estimates derived from such studies may be misleading for newly diagnosed women attempting to make the difficult choice between breast conservation and bilateral mastectomy.

Taken together, the results of the available series suggest, at least up to 10 years of follow up, that women with $B R C A 1 / B R C A 2$ germline mutations have a risk for ipsilateral recurrence that is similar to that of other young women. Studies based on series of prevalent cases $[8,26,27]$ suggest, however, that women who are longterm survivors may have an increased risk of new second primary malignancies within the treated breast. This interpretation is supported by a further analysis of cases reported by Haffty and colleagues [28], in which all eight patients with deleterious BRCA1/BRCA2 mutations had new primary ipsilateral breast cancer, whereas patients without deleterious mutations had both true recurrences and new primary breast cancers $(P=0.06)$. The cancers occurring in BRCA1/BRCA2 carriers occurred at a mean time interval of 9.6 years following the initial diagnosis.

Women with BRCA1/BRCA2 mutations are at substantial increased risk for metachronous contralateral breast cancer throughout the follow-up period. Although this increased contralateral risk could reflect an increased sensitivity to radiation-induced malignancies initiated by scatter from adjuvant radiotherapy, the contralateral incidence rate is similar to that observed in affected mutation carriers after mastectomy [29] and in prospectively followed cohorts of heterozygotes [30,31], which suggests that the observed contralateral breast cancers are most likely the direct result of the underlying genetic predisposition. The apparent paradox of differential ipsilateral and contralateral risk, as well as differences in estimates of ipsilateral risk according to duration of follow up, may be explained by a model that proposes that women presenting with BRCA1/BRCA2-associated breast cancer have multiple foci within both breasts at various stages of evolution toward malignancy. These foci may be eliminated or substantially retarded by adjuvant radiotherapy of the initially affected breast, preventing or delaying their appearance as metachronous ipsilateral cancers. In the untreated contralateral breast, however, occult lesions existing at the time of initial diagnosis could proceed unimpeded in their progression to malignancy, resulting in an unaltered risk for contralateral cancer. Extending the hypothesis, the continued presence of the genetic predisposition may permit the process of carcinogenesis in the affected breast to begin anew once the radiation treatment was completed, and, after a delay, metachronous breast cancers would begin to appear in the treated and untreated breasts at similar rates. This hypothetical model could be tested by careful pathologic examination of breasts of women with BRCA1/BRCA2 mutations undergoing either therapeutic or prophylactic mastectomy to assess the prevalence of occult premalignant and malignant lesions. The results of early reports are conflicting, but there is some evidence for an excess of premalignant changes, particularly for BRCA2 mutation carriers [32-34].

Nonsurgical options for breast cancer risk reduction in women with BRCA1/BRCA2 mutations are limited. A previous case-control study [35] suggested that tamoxifen reduced the risk for contralateral cancer by nearly $50 \%$ in mutation carriers, but this benefit was not observed in a prospective trial of primary prevention among unaffected women with BRCA1 mutations [36]. In the present study, a trend toward a reduction in contralateral breast cancer was seen in mutation carriers who received the drug, although this did not achieve statistical significance. Because the number of women with mutations who received tamoxifen was small, the present series cannot satisfactorily address whether the benefit of tamoxifen in reducing contralateral risk varies between women with $B R C A 1$ and those with BRCA2 mutations. It is of interest that the degree of contralateral risk reduction experienced by the mutation carriers taking tamoxifen in the study was similar to that reported in the previous case-control study, and there was no clear difference between the effects observed in BRCA1 and BRCA2 mutation carriers, but further studies of larger numbers of women are needed before these data can be used to guide clinical practice.

Retrospective anonymized studies such as the one reported here may be more easily performed in populations with a high prevalence of specific founder BRCA1/BRCA2 mutations, such as the Ashkenazim. Nonfounder mutations are not identified with this design, and a small number of individuals will thus be misclassified as 'mutation negative' when, in fact, they carry a unique dele- 
terious alteration. However, the number of such cases is likely to be small. In a recent report of 322 Ashkenazi individuals who underwent full sequence analysis of BRCA1 and BRCA2 after negative founder mutation testing, only six $(1.9 \%)$ were found to carry a unique mutation [37]. Because women undergoing complete sequencing were probably encouraged to do so because of a family history of breast or ovarian cancer, the prevalence of unique mutations is likely to be even lower in an unselected population of breast cancer patients such as those reported in the present study. Thus, false-negative classification is unlikely to have significantly affected the results of this study. Nonetheless, the results of the study may not be applicable to all women with BRCA1/BRCA2 mutations. The majority of mutation carriers in the study carried either BRCA1 185delAG (32 out of 42 [76\%] of all BRCA1 mutation carriers) or BRCA2 6174 delT. It is possible that other mutant alleles may confer different risks for recurrence.

\section{Conclusion}

This combined study demonstrates that women with specific BRCA1/BRCA2 mutations who develop breast cancer are at increased risk for death from their disease, particularly if the mutation is in BRCA1. For up to 10 years after diagnosis, the risk for metachronous ipsilateral cancer is similar to that in women without mutations, but the risk for contralateral disease is substantially higher. Taken together, these findings suggest that the possibility of BRCA1/BRCA2-associated breast cancer should be taken into account with other factors when making decisions regarding radiotherapy and adjuvant chemotherapy, but should not be used as a sole factor to determine the appropriateness of BCT. Adjuvant tamoxifen should be given when appropriate to $B R C A 1 / B R C A 2$ mutation carriers with hormone receptor positive breast cancer, but despite promising data, the true effectiveness of this agent in reducing contralateral breast cancer risk in this group of women remains uncertain.

\section{Competing interests}

None declared

\section{Acknowledgements}

This work was supported by US Army Medical Research and Materiel Command DAMD17-98-1-8112, Canadian Genetic Diseases Network and Susan G Komen Foundation (WDF), US Army Medical Research and Materiel Command DAMD 17-01-1-0325 and American Cancer Society PRTA-38 (MR), Fonds de perfectionnement des Hôpitaux Universitaires de Genève, Geneva, Switzerland (POC), and Danziger Foundation and Breast Cancer Research Foundation (KO). WDF is a Senior Clinicien Chercheur Boursier of the Fonds de la Recherche en Santé du Québec. We wish to thank Nancy Hamel and Jean-Sébastien Brunet for technical and statistical assistance.

\section{References}

1. Miki Y, Swensen J, Shattuck-Eidens D, Futreal PA, Harshman K, Tavtigian S, Liu Q, Cochran C, Bennett LM, Ding W, Bell R, Rosenthal J, Hussey C, Tran T, McClure M, Frye C, Hattier T, Phelps R, Haugen-Strano A, Katcher H, Yakumo K, Gholami Z,
Shaffer D, Stone S, Bayer S, Wray C, Bogden R, Dayananth P, Ward J, Tonin P, Narod S, Bristow PK, Norris FH, Helvering L, Morrison P, Rostock P, Lai M, Barrett JC, Lewis C, Neuhausen S Cannon-Albright L, Goldgar D, Wiseman R, Kamb A, Skolnick $\mathrm{MH}$ : A strong candidate for the breast and ovarian cancer susceptibility gene BRCA1. Science 1994, 266:66-71.

2. Wooster R, Bignell G, Lancaster J, Swift S, Seal S, Mangion J, Collins N, Gregory S, Gumbs C, Micklem G, Barfoot R, Hamoudi R, Patel S, Rice C, Biggs P, Hashim Y, Smith A, Connor F, Arason A, Gudmundsson J, Ficenec D, Kelsell D, Ford D, Tonin P, Bishop DT, Spurr NK, Ponder BAJ, Eeles R, Peto J, Devilee P, Cornelisse C,Lynch H, Narod S, Lenoir G, Egilsson V, Bjork Barkadottir R, Easton DF, Bentley DR, Futreal PA, Ashworth A, Stratton MR: Identification of the breast cancer susceptibility gene BRCA2. Nature 1995, 378:789-792.

3. Foulkes WD, Wong N, Brunet JS, Bégin LR, Zhang JC, Martinez JJ, Rozen F, Tonin PN, Narod SA, Karp SE, Pollak MN: Germ-line BRCA1 mutation is an adverse prognostic factor in Ashkenazi Jewish women with breast cancer. Clin Cancer Res 1997, 3: 2465-2469.

4. Stoppa-Lyonnet D, Ansquer $\mathrm{Y}$, Dreyfus H, Gautier C, GauthierVillars $M$, Bourstyn $E$, Clough KB, Magdelenat $H$, Pouillart $P$, Vincent-Salomon A, Fourquet A, for the Institute Curie Breast Cancer Group, Asselain B: Familial invasive breast cancer: worse outcome related to BRCA1 mutations. J Clin Oncol 2000, 18:4053-4059.

5. Hamann U, Sinn HP: Survival and tumor characteristics of German hereditary breast cancer patients. Breast Cancer Res Treat 2000, 59(2):185-192.

6. Møller P, Borg A, Evans DG, Haites N, Reis MM, Vasen H, Anderson E, Steel CM, Apold J, Goudie D, Howell A, Lalloo F, Maehle L, Gregory H, Heimdal K: Survival in prospectively ascertained familial breast cancer: analysis of a series stratified by tumour characteristics, BRCA mutations and oophorectomy. Int J Cancer 2002, 101:555-559.

7. Verhoog LC, Brekelmans CT, Seynaeve C, van den Bosch LM, Dahmen G, van Geel AN, Tilanus-Linthorst MM, Bartels CC, Wagner A, van den Ouweland A, Devilee P, Meijers-Heijboer EJ, Klijn JG: Survival and tumor characteristics of breast-cancer patients with germline mutations of BRCA1. Lancet 1998, 351:316-321.

8. Pierce LJ, Strawderman M, Narod SA, Oliviotto I, Eisen A, Dawson L, Gaffney D, Solin LJ, Nixon A, Garber J, Berg C, Isaacs C, Heimann R, Olopade OI, Haffty B, Weber BL: Effect of radiotherapy after breast-conserving treatment in women with breast cancer and germline BRCA1/2 mutations. J Clin Oncol 2000, 18:3360-3369.

9. Verhoog LC, Brekelmans CT, Seynaeve C, Dahmen G, van Geel AN, Bartels CC, Tilanus-Linthorst MM, Wagner A, Devilee $P$, Halley DJ, van den Ouweland AM, Meijers-Heijboer EJ, Klijn JG: Survival in hereditary breast cancer associated with germline mutations of BRCA2. J Clin Oncol 1999, 17:3396-3402.

10. Loman N, Johannsson O, Bendahl PO, Dahl N, Einbeigi Z, Gerdes A-M, Borg $\mathrm{A}$, Olsson $\mathrm{H}$ : Prognosis and clinical presentation of BRCA2-associated breast cancer. Eur J Cancer 2000, 36: 1365-1373.

11. Struewing JP, Abeliovich D, Peretz T, Avishai N, Kaback MM, Collins FS, Brody LC: The carrier frequency of the BRCA1 185delAG mutation is approximately 1 percent in Ashkenazi Jewish individuals. Nature Genet 1995, 11:198-200.

12. Oddoux C, Struewing JP, Clayton CM, Neuhausen S, Brody LC, Kaback M, Haas B, Norton L, Borgen P, Jhanwar S, Goldgar D, Ostrer H, Offit K: The carrier frequency of the BRCA2 6174delT mutation among Ashkenazi Jewish individuals is approximately 1-percent. Nat Genet 1996, 14:188-190.

13. Roa BB, Boyd AA, Volcik K, Richards CS: Ashkenazi Jewish population frequencies for common mutations in BRCA1 and BRCA2. Nat Genet 1996, 14:185-187.

14. Kauff ND, Perez-Segura $P$, Robson ME, Scheuer L, Siegel B, Schluger A, Rapaport B, Frank TS, Nafa K, Ellis NA, Parmigiani G, Offit K: Incidence of non-founder BRCA1 and BRCA2 mutations in high risk Ashkenazi breast and ovarian cancer families. J Med Genet 2002, 39:611-614.

15. Robson M, Levin D, Federici M, Satagopan J, Bogolminy F, Heerdt A, Borgen P, McCormick B, Hudis C, Norton L, Boyd J, Offit K. Breast conservation therapy for invasive breast cancer in Ashkenazi women with BRCA gene founder mutations. J Nat/ Cancer Inst 1999, 91:2112-2117. 
16. Goffin JR, Chappuis PO, Bégin LR, Wong N, Brunet JS, Hamel N, Paradis AJ, Boyd J, Foulkes WD: Impact of germline BRCA1 mutations and overexpression of p53 on prognosis and response to treatment following breast carcinoma: 10-year follow up data. Cancer 2003, 97:527-536.

17. Gray RJ: A class of K-sample tests for comparing the cumulative incidence of a competing risk. Ann Stat 1988, 16:11411154.

18. Fine JP, Gray RJ: A proportional hazards model for the subdistribution of a competing risk. J Am Stat Assoc 1999, 94:496509.

19. Robson ME, Boyd J, Borgen PI, Cody HS III: Hereditary breast cancer. Curr Prob/ Surg 2001, 38:387-480.

20. Foulkes WD, Rosenblatt J, Chappuis PO: The contribution of inherited factors to the clinicopathological features and behavior of breast cancer. J Mammary Gland Biol Neoplasia 2001, 6:453-465.

21. Lakhani SR, Jacquemier J, Sloane JP, Gusterson BA, Anderson TJ, van de Vijver MJ, Farid LM, Venter D, Antoniou A, Storfer-Isser A, Smyth E, Steel CM, Haites N, Scott RJ, Goldgar D, Neuhausen S, Daly PA, Ormiston W, McManus R, Scherneck S, Ponder BAJ, Ford D, Peto J, Stoppa-Lyonnet D, Bignon YJ, Struewing JP, Spurr NK, Bishop DT, Klijn JGM, Devilee P, Cornelisse CJ, Lasset C, Lenoir G, Barkardottir RB, Egilsson V, Hamann U, Chang-Claude J, Sobol $\mathrm{H}$, Weber B, Stratton MR, Easton DF: Multifactorial analysis of differences between sporadic breast cancers and cancers involving BRCA1 and BRCA2 mutations. J Nat/ Cancer Inst 1998, 90:1138-1145.

22. Bhattacharyya A, Ear US, Koller BH, Weichselbaum RR, Bishop DK: The breast cancer susceptibility gene BRCA1 is required for subnuclear assembly of Rad51 and survival following treatment with the DNA cross-linking agent cisplatin. J Biol Chem 2000, 275:23899-23903.

23. Moynahan ME, Cui TY, Jasin M: Homology-directed dna repair, mitomycin-c resistance, and chromosome stability is restored with correction of a Brca1 mutation. Cancer Res 2001, 61: $4842-4850$

24. Tassone P, Tagliaferri P, Perricelli A, Blotta S, Quaresima B, Martelli ML, Goel A, Barbieri V, Costanzo F, Boland CR, Venuta S: BRCA1 expression modulates chemosensitivity of BRCA1defective HCC1937 human breast cancer cells. Br J Cancer 2003, 88:1285-1291.

25. Chappuis PO, Kaputa L, Bégin LR, Wong N, Brunet JS, Narod SA, Slingerland J, Foulkes WD. Germ-line BRCA1/2 mutations and p27(Kip1) protein levels independently predict outcome after breast cancer. J Clin Oncol 2000, 18:4045-4052.

26. Turner BC, Harrold E, Matloff E, Smith T, Gumbs AA, Beinfield M, Ward B, Skolnick M, Glazer PM, Thomas A, Haffty BG: BRCA1/BRCA2 germline mutations in locally recurrent breast cancer patients after lumpectomy and radiation therapy: Implications for breast-conserving management in patients with BRCA1/BRCA2 mutations. J Clin Oncol 1999, 17:30173024.

27. Haffty BG, Harrold E, Khan AJ, Pathare P, Smith TE, Turner BC, Glazer PM, Ward B, Carter D, Matloff E, Bale AE, Alvarez-Franco $\mathrm{M}$ : Outcome of conservatively managed early-onset breast cancer by BRCA1/2 status. Lancet 2002, 359:1471-1477.

28. Smith TE, Lee D, Turner BC, Carter D, Haffty BG: True recurrence vs. new primary ipsilateral breast tumor relapse: an analysis of clinical and pathologic differences and their implications in natural history, prognoses, and therapeutic management. Int J Radiat Oncol Biol Phys 2000, 48:1281-1289.

29. Easton DF, Ford D, Bishop DT: Breast and ovarian cancer incidence in BRCA1-mutation carriers. Breast Cancer Linkage Consortium. Am J Hum Genet 1995, 56:265-271.

30. Brekelmans CT, Seynaeve C, Bartels CC, Tilanus-Linthorst MM, Meijers-Heijboer EJ, Crepin CM, van Geel AA, Menke M, Verhoog LC, van den OA, Obdeijn IM, Klijn JG: Effectiveness of breast cancer surveillance in BRCA1/2 gene mutation carriers and women with high familial risk. J Clin Oncol 2001, 19:924-930.

31. Scheuer L, Kauff N, Robson M, Kelly B, Barakat R, Satagopan J, Ellis N, Hensley M, Boyd J, Borgen P, Norton L, Offit K: Outcome of preventive surgery and screening for breast and ovarian cancer in BRCA mutation carriers. J Clin Oncol 2002, 20:12601268.

32. Hoogerbrugge N, Bult $P$, Widt-Levert LM, Beex LV, Kiemeney LA, Ligtenberg MJ, Massuger LF, Boetes C, Manders P, Brunner HG:
High prevalence of premalignant lesions in prophylactically removed breasts from women at hereditary risk for breast cancer. J Clin Oncol 2003, 21:41-45.

33. Adem C, Reynolds C, Soderberg CL, Slezak JM, McDonnell SK, Sebo TJ, Schaid DJ, Myers JL, Sellers TA, Hartmann LC, Jenkins RB. Pathologic characteristics of breast parenchyma in patients with hereditary breast carcinoma, including BRCA1 and BRCA2 mutation carriers. Cancer 2003, 97:1-11.

34. Kauff ND, Brogi E, Scheuer L, Pathak DR, Borgen PI, Hudis CA, Offit K, Robson ME: Epithelial lesions in prophylactic mastectomy specimens from women with BRCA mutations. Cancer 2003, 97:1601-1608

35. Narod SA, Brunet JS, Ghadirian P, Robson M, Heimdal K, Neuhausen SL, Stoppa-Lyonnet D, Lerman C, Pasini B, de los Rios P, Weber B, Lynch H: Tamoxifen and risk of contralateral breast cancer in BRCA1 and BRCA2 mutation carriers: a case-control study. Hereditary Breast Cancer Clinical Study Group. Lancet 2000, 356:1876-1881.

36. King MC, Wieand S, Hale K, Lee M, Walsh T, Owens K, Tait J, Ford L, Dunn BK, Costantino J, Wickerham L, Wolmark N, Fisher $B$ : Tamoxifen and breast cancer incidence among women with inherited mutations in BRCA1 and BRCA2: National Surgical Adjuvant Breast and Bowel Project (NSABP-P1) Breast Cancer Prevention Trial. JAMA 2001, 286:2251-2256.

37. Frank TS, Deffenbaugh AM, Reid JE, Hulick M, Ward BE, Lingenfelter B, Gumpper KL, Scholl T, Tavtigian SV, Pruss DR, Critchfield GC: Clinical characteristics of individuals with germline mutations in BRCA1 and BRCA2: analysis of 10,000 individuals. J Clin Oncol 2002, 20:1480-1490.

\section{Correspondence}

William D Foulkes, MB, PhD, Program in Cancer Genetics, Departments of Oncology and Human Genetics, McGill University, Montreal, QC, Canada. Tel: 5149341934 x44121; fax: 514934 8273; e-mail: william.foulkes@mcgill.ca 